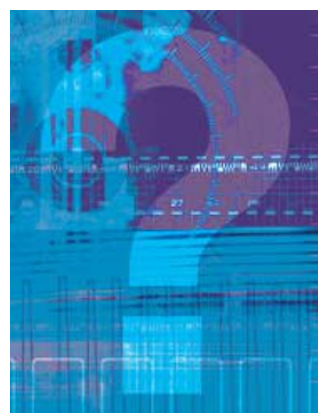

\title{
HIGHLIGHTING THE PITFALLS AND POSSIBILITIES OF DRUG RESEARCH
}

We're all well acquainted with the unbounded optimism that tends to accompany discussions of the therapeutic potential of life science research. Each new research methodology or newly discovered target family is heralded as the next great hope. Although applauding this enthusiasm, we also recognize that, sadly, the best-laid plans can, and often do, go awry. Things usually turn out to be more complicated than first expected, and success often comes more slowly than predicted, if at all.

In an attempt to avoid the setbacks that frequently confound drug research programmes, industrial scientists are making ever-greater efforts to collaborate with their colleagues in universities; not only is it clearly better to have more brains devoted to the problem, but academic scientists may have different perspectives on their research area. Basic scientists, with more time to probe the 'complications' of each field, may be able to bring detailed knowledge, gathered in an enviroment less constrained by concerns of immediate utility, to the problems of applied research and help avoid the pitfalls of drug development.

In this spirit, our new 'Twenty Questions' section of Nature Reviews Drug Discovery will provide an occasional forum for airing academic scientists' thoughts on questions of fundamental importance to a research field exciting great therapeutic interest. The format is simple: we pose 20 questions to 20 of the world's leading authorities in a field, leaving them free to answer those questions that most interest them, and we print their answers with minimal editing. In some cases, the diversity of answers to a single question will illustrate a wide spectrum of opinions; in others, the similarity of the participants' answers will demonstrate the existence of consensus on an issue.

Although all of the participants have had the chance to view each other's answers, they have not been given the opportunity to directly reply to one another. The physicist Richard Feynman once described how, upon joining the highly elite group of scientists working on the Manhattan Project, he was invited to a roundtable to discuss a key question. He was amazed to find that everybody at the meeting spoke only once, giving their view on the issue but not contradicting anyone else's views. At first he was furious that the people he thought correct didn't reiterate their points in the face of what he took to be the stupidity of those who believed differently. But at the end of the meeting, the Chairman declared that, having heard all the arguments, it was perfectly clear to all assembled which was the most sensible answer, and so the committee would follow that path. This, Feynman concluded, was how intelligent people held meetings.

The area of ion channel research is a particularly suitable topic with which to launch this section. Thought by many to represent one of the largest sources of potential new targets for drugs, and implicated in the pathogenesis of a vast array of diseases, ion channels are also illustrative of the sort of complexity that so frequently dashes drug development hopes. Their ubiquitous expression profiles make regionally selective targeting a problem, and similarities in their pore structures lead to cross reactivity and attendant side-effect problems, as observed with long-QT syndrome, for instance. Ion channels have also so far proved to be uniquely resistant to high-throughout approaches to screening for potential modulators. Whether their hidden promise will soon become less 'hidden' is an issue that you will hopefully be better able to resolve for yourself after reading this article.

These questions and answers appeared in a preliminary form as part of a joint report produced by Nature Reviews Drug Discovery and Decision Resources entitled Ion Channel Modulators: Emerging Therapeutic Opportunities, which sought to present the views of academic scientists side-byside with those of their industrial counterparts and strategic planners. We have more recently contributed to a second report that examines the therapeutic potential of G-protein-coupled receptors (GPCRs), and a further Twenty Questions section on GPCRs will be published in Nature Reviews Drug Discovery later this year.

As discussed in this month's editorial on page 191, one of our constant concerns at Nature Reviews Drug Discovery is that people don't ask enough questions. For this month at least, we've hopefully redressed the balance.

Clare Ellis and Adam Smith doi:10.1038/nrd1332 